\title{
Timed-flat infusion of 5-fluorouracil with docetaxel and oxaliplatin as first-line treatment of gastroesophageal adenocarcinoma: A single institution experience with the FD/FOx regimen
}

\author{
ALESSIO CORTELLINI $^{1,2}$, KATIA CANNITA ${ }^{1}$, ALESSANDRO PARISI ${ }^{1,2}$, OLGA VENDITTI $^{1}$, \\ PAOLA LANFIUTI BALDI ${ }^{1}$, BERARDO DE BERARDIS ${ }^{4}$, ROBERTO VICENTINI ${ }^{3}$, VINCENZO VICENTINI ${ }^{3}$, \\ LUCILLA VERNA $^{2}$, GIAMPIERO PORZIO ${ }^{1,2}$ and CORRADO FICORELLA ${ }^{1,2}$ \\ ${ }^{1}$ Medical Oncology Unit, San Salvatore Hospital, University of L'Aquila; \\ ${ }^{2}$ Department of Biotechnological and Applied Clinical Sciences, University of L'Aquila; \\ ${ }^{3}$ Department of Hepatobiliary and Pancreatic and Emergency Surgery, San Salvatore Hospital, L'Aquila I-67100; \\ ${ }^{4}$ Department of General Surgery, 'Villa Anna' Clinic, San Benedetto del Tronto 63074, Italy
}

Received December 19, 2017; Accepted May 9, 2018

DOI: $10.3892 /$ or.2018.6475

\begin{abstract}
To date, there is no consensus regarding first-line chemotherapy for patients with HER2-negative, locally advanced/metastatic gastric cancer ( $\mathrm{a} / \mathrm{m} \mathrm{GC})$. In the present study we reported a retrospective case-series of patients treated with a weekly regimen containing timed-flat infusion of 5-fluorouracil (TFI/5-FU), docetaxel and oxaliplatin. From June 2007 to July 2017, 32 consecutive a/m GC patients were treated with first-line standard (st) or modulated (mod) 'FD/FOx' regimen: Weekly $12 \mathrm{~h}$ (from 10.00 p.m. to 10.00 a.m.) TFI/5-FU for two consecutive nights at $900 \mathrm{mg} / \mathrm{m}^{2} /$ day, associated to weekly alternating docetaxel, $50 \mathrm{mg} / \mathrm{m}^{2}$ and oxaliplatin, $80 \mathrm{mg} / \mathrm{m}^{2}$. The median age of the patients was 60 years and their Eastern Cooperative Oncology Group-performance status (ECOG-PS) was as follows: i) ECOG-PS 0/1, $(\mathrm{n}=28,87.5 \%)$; and ii) ECOG-PS $2(\mathrm{n}=4$, $12.5 \%$ ). Patient activity, efficacy and safety data were collected and subgroup analyses were conducted among patients treated with st and mod FD/FOx. In the intention-to-treat (ITT) analysis, the objective response rate (ORR) was $75 \%$ (95\% CI, 53-90) and the disease control rate (DCR) was $87.5 \%$ (95\% CI, 67.6-97.3). After a median follow-up of 16 months, median progression-free survival (PFS) and median overall survival (OS) were 14.0 and 19.0 months, respectively. The received dose-intensities were $\sim 80 \%$ of the standard doses for each agent. The most relevant treatment-related grade 3 adverse
\end{abstract}

Correspondence to: Dr Alessio Cortellini, Department of Biotechnological and Applied Clinical Sciences, University of L'Aquila, Via Vetoio, L'Aquila I-67100, Italy

E-mail: alessiocortellini@gmail.com

Key words: gastric cancer, docetaxel oxaliplatin and 5-fluorouracil combination chemotherapy, intensive chemotherapy events were: Neutropenia (40.6\%), asthenia (18.7\%) and diarrhea (18.7\%). The only treatment-related grade 4 adverse event was neutropenia (9.3\%). No febrile neutropenia was observed and none of the patients died as a result of adverse events. FD/FOx regimen appeared to be a feasible option as a first-line treatment of a/m GC patients, especially in case of high-tumor burden, with the need of rapid tumor shrinkage and disease-related symptoms palliation.

\section{Introduction}

The majority of patients with gastric cancer (GC) already presents with advanced disease at the time of diagnosis or develops metastases after treatment with curative intent. In these patients, chemotherapy can provide palliation of symptoms, improved survival and quality of life, compared to best supportive care (BSC) $(1,2)$.

Combination therapies have demonstrated substantially higher response rates and survival compared to monotherapy $(3,4)$. Although the optimal regimen for first-line chemotherapy of locally advanced/metastatic $(\mathrm{a} / \mathrm{m})$ GC patients is well defined in tumors which overexpress human epidermal growth factor receptor-2 (HER2) (5), this is not the case for HER2-negative tumors, which are $~ 80 \%$ of the cases. In these patients the question of whether a three-drug regimen is more effective than a potentially less toxic doublet remains controversial.

According to the National Comprehensive Cancer Network (NCCN) guidelines of 2016 two-drug regimens are preferred and three-drug cytotoxic regimes should be reserved for medically fit patients with good performance status (PS) and access to frequent evaluation (6). The European Society for Medical Oncology (ESMO) guidelines of 2016 state that "combination regimens incorporating a platinum agent and a fluropyrimidine are generally used and it remains controversial whether a triplet regimen is needed' (7).

A recent systematic literature review and meta-analysis has revealed a significant improvement in overall survival (OS), 
progression-free survival (PFS) and objective response rate (ORR) in favor of a triplet over a doublet chemotherapy, especially when containing fluoropyrimidines, cisplatin and taxane, at the expense of major incidence of grade 3-4 thrombocytopenia (6.2 vs. $3.7 \%)$, infections (10.2 vs. $6.4 \%)$ and mucositis $(9.7$ vs. $4.7 \%)(8)$. A real-world data analysis and a network meta-analysis have recently revealed that anthracycline-based triplets do not improve the efficacy of platinum-fluoropyrimidine doublets in terms of ORR, median OS and median PFS as first-line treatment, and present with greater toxicity and a major impact on the quality of life (QoL) $(9,10)$.

The combination of docetaxel, cisplatin and 5FU (DCF) has been evaluated in randomized clinical trials. In the V325 trial, a randomized multinational phase III study, 445 untreated $\mathrm{a} / \mathrm{m}$ GC patients were randomized to receive either DCF every 3 weeks or cisplatin and 5-FU (CF). At a median follow-up of 13.6 months, median time to progression (5.6 vs. 3.7 months), median OS (9.2 vs. 8.6 months) and ORR (37 vs. $25 \%)$ were significantly higher with DCF than CF, with a two-year survival rate of 18 and $9 \%$, respectively. The modified DCF $(\mathrm{mDCF})$ regimen has been demonstrated to have at least equal efficacy and lower toxicity compared to standard DCF chemotherapy in a phase II trial (11). In addition, a recent phase II trial (GATE trial) has evaluated the efficacy and tolerability of docetaxel plus oxaliplatin with or without infusional 5-FU (TEF and TE, respectively) or capecitabine (TEX) in a/m GC patients (12). The addition of docetaxel to oxaliplatin and 5-FU proved to have a better safety profile and was also associated with higher ORR, longer median PFS and median OS (47\%, 7.7 and 14.6 months, respectively) compared to docetaxel, oxaliplatin and capecitabine $(26 \%, 5.6$ and 11.3 months, respectively). The frequency of grade 3 or 4 adverse events was lower among patients treated with TEF (25\%) compared to those treated with TE $(37 \%)$ or TEX (38\%).

In addition, a triplet regimen with docetaxel demonstrated efficacy in the neoadjuvant therapy setting in locally advanced resectable esophago-gastric cancer, significantly increasing the proportion of patients achieving pathological complete regression compared with ECF/ECX in the multicenter, open-label, randomised phase 2/3 trial FLOT4-AIO (13).

In order to increase the tolerability of 5-FU in combination with irinotecan in metastatic colorectal cancer patients, we have previously developed an alternative way of administration of 5-FU, called timed-flat infusion (TFI), which consisted in a 12-h nocturnal flat infusion (from 10:00 p.m. to 10:00 a.m.), without 5-FU bolus and folinic acid (14). To date no experimental evidence has supported that the modulation of folinic acid enhanced the antitumor activity of infusional 5-FU at its maximum tolerated dose (15-17). TFI/5-FU, exploits the increased activity in mononuclear cells of dihydropyrimidine dehydrogenase, the enzyme involved in 5-FU intracellular catabolism, and the reduced proliferation of the healthy tissue most damaged by 5-FU (the bone marrow and oral/rectal mucosa) during the evening hours (18-21). Subsequently, we developed a triplet schedule, called FIr/FOx, containing irinotecan and oxaliplatin administered every other week, associated with TFI/5-FU two nights a week (22), and the FIrB/FOx schedule, by adding bevacizumab to this triplet regimen (23), with manageable toxicity and high received dose intensities (rDI).
On the basis of these previous findings, we designed the FD/FOx regimen, a triplet schedule containing weekly alternated docetaxel and oxaliplatin, associated with TFI/5-FU two nights a week. In the present study we reported a single institution retrospective analysis of a/m GC patients treated with first line FD/FOx, in order to assess whether this alternative way of administration of 5-FU, can allow to treat more patients with an intensive regimen in common clinical practice.

\section{Materials and methods}

Patient eligibility. This retrospective analysis evaluated consecutive a/m GC patients treated with FD/FOx regimen, from June 2007 to July 2017. Patients were eligible if they had histologically confirmed diagnosis of GC (gastric or esophago-gastric adenocarcinoma); aged, 18-80 years; Eastern Cooperative Oncology Group Performance Status (ECOG-PS) $\leq 2$; adequate hematological, renal and hepatic functions. The treatments were tailored according to patient fitness level which was prevalently defined according to age [non-elderly ( $<65$ years), young-elderly ( $\geq 65,<75$ years) and old-elderly ( $\geq 75$ years)], ECOG-PS and comorbidities. Comorbidities were evaluated by the Cumulative Index Rating Scale (CIRS) (24) as follows: Primary CIRS stage consisted of independent instrumental activity of daily living (IADL) and absent or mild-grade comorbidities; intermediate CIRS stage consisted of dependent or independent IADL and less than three mild- or moderate-grade comorbidities; secondary CIRS stage, consisting of more than three comorbidities or a severe comorbidity, with or without dependent IADL. Patients with performance status (PS) 3 were not eligible. All patients provided written, informed consent to treatment. The procedures followed were in accordance with the ethical standards of the local responsible committees on human experimentation, namely the Comitato Etico per le province di L'Aquila e Teramo.

Schedules of therapeutic regimens. Standard (st) FD/FOx regimen (Fig. 1) is a schedule of weekly 12-h (from 10.00 p.m. to 10.00 a.m.) TFI/5-FU administered for two consecutive nights at $900 \mathrm{mg} / \mathrm{m}^{2} / \mathrm{day}$, associated to alternating docetaxel $50 \mathrm{mg} / \mathrm{m}^{2}$ on days 1 and 15 , and oxaliplatin $80 \mathrm{mg} / \mathrm{m}^{2}$ on days 8 and 22, with cycles repeated every four weeks. 5-FU was administered by a portable pump (CADD Plus, SEVIT) using a central venous access device (port-a-cath or peripherally inserted central catheter). Modified (mod) FD/FOx was defined by any projected dose reduction compared to the standard one, due to age, PS and/or comorbidities. Dose level reductions were not standardized; as a general rule, when a modulation was required, doses of each drug were reduced within the following ranges: 5 -FU $800-750 \mathrm{mg} / \mathrm{m}^{2} /$ day, docetaxel $45-40 \mathrm{mg} / \mathrm{m}^{2}$ and oxaliplatin $70 \mathrm{mg} / \mathrm{m}^{2}$. Specifically in patients with a greater risk of gastrointestinal toxicity (peritoneal carcinomatosis, irregular bowel motion, recent surgeries), priority was given to the dose reduction of 5-FU. In patients with a greater risk of malnutrition and leuco/neutropenia (un-resected primary tumor, hypoalbuminemia, risk of infections), priority was given to the dose reduction of docetaxel. In patients with a greater risk of neurotoxicity and nephrotoxicity (diabetes, mild impaired renal function), priority was given to the dose reduction of oxaliplatin. 

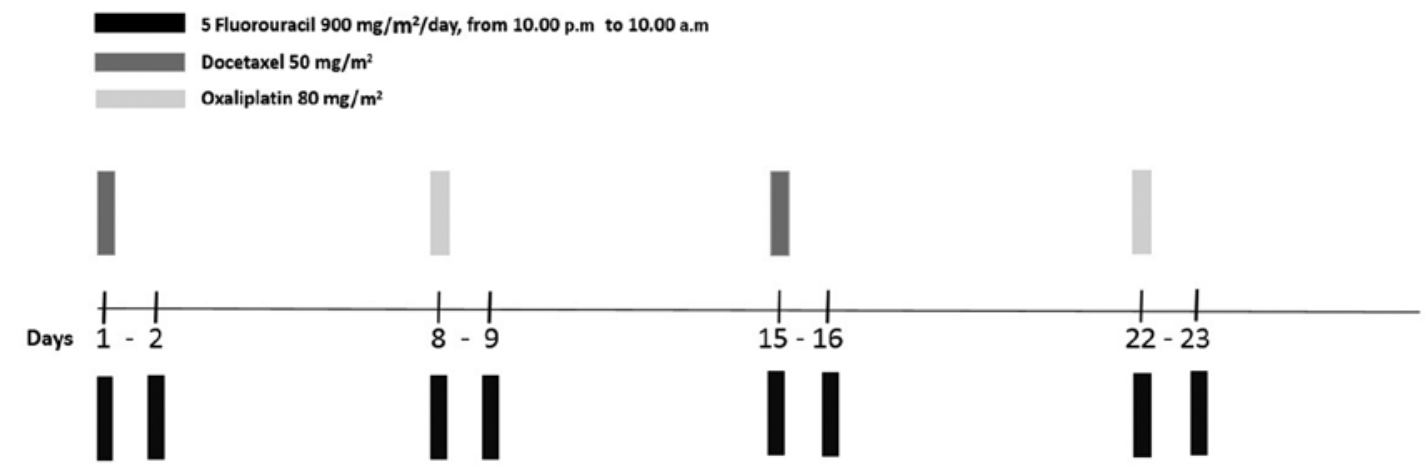

Figure 1. Graphic representation of the FD/FOx schedule of administration.

HER2 assessment. HER 2 analysis was performed with immunohistochemistry on paraffin embedded tissue from the primary tumor and/or metastatic site (HercepTest; Dako Denmark A/S; Agilent Technologies GmbH, Waldbronn, Germany).

Study design and statistical analysis. A retrospective analysis of consecutive a/m GC patients, treated with first line FD/FOx, was conducted to evaluate the safety, activity and efficacy of the regimen in clinical practice. This is a 'regimen-oriented' collection, in order to assess the feasibility of FD/FOx in several stages of the disease. Positive peritoneal cytology was considered metastatic disease (25), therefore four patients, treated with st FD/FOx, with peritoneal cytology-limited disease were included in the efficacy and safety analysis, but not in the activity one. One patient with locally advanced disease, treated with st FD/FOx, was included in the activity and safety analysis, but not in the efficacy one. Subgroup analysis was performed among patients treated with standard and modified regimens. The clinical evaluation of patient response was performed by computed tomography scan. Positron-emission tomography was added based on the investigators assessment. Follow-up was scheduled every three months up to progression or death. The clinical criteria of activity and efficacy were ORR, DCR, PFS and OS. ORR and DCR were evaluated according to the RECIST criteria (26). Median PFS and median OS were evaluated using the Kaplan-Meier method (27). ORR was defined as the rate of patients experiencing an objective response [complete response (CR), or partial response (PR)] as the best response. DCR was defined as the rate of patients who experienced an objective response or demonstrated stable disease (SD) as the best response to treatment. PFS was defined as the length of time from the beginning of the treatment until the disease progression or death (from any cause) or until the last contact. OS was defined as the length of time between the beginning of treatment until death or upto the last contact. In the subgroup analysis Fisher's exact test (28) was used to compare ORR and log-rank test (29) was used to compare median PFS and OS, according to first line regimens. Toxicity was registered according to the National Cancer Institute Common Toxicity Criteria (version 4.0; https://www.eortc. be/services/doc/ctc/CTCAE_4.03_2010-06-14_QuickReference_ $5 \times 7 . p d f)$. Median received dose intensities (rDI) were calculated 'per cycle' as $\mathrm{mg} / \mathrm{m}^{2} /$ week; percentage values were referred to standard regimens for each agent. The data cut-off period was on July 2017.

\section{Results}

Patient features. From June 2007 to July 2017, 32 consecutive $\mathrm{a} / \mathrm{m}$ GC patients, were treated with first line FD/FOx regimen: 22 patients were treated with standard regimen and 10 patients were treated with modified regimens due to age, ECOG-PS and/or comorbidities. The clinical features of all 32 patients are presented in Table I: Male/Female ratio, 23/9; median age, 60 years (range, 41-80); PS 0, 10 (31.2\%), PS 1, 18 (56.3\%), PS 2, $4(12.5 \%)$. The metastatic sites were as follows: Liver $11(34.4 \%)$, peritoneum/ascites $21(65.6 \%)$, lymph nodes $17(53.1 \%)$, others $5(15.6 \%)$; $4(12.5 \%)$ patients had peritoneal cytology-limited disease. Two $(6.3 \%)$ patients had primary tumor of the gastroesophageal junction and $30(93.8 \%)$ of the stomach. Fourteen $(43.7 \%)$ patients had unresected primary tumor.

Activity and efficacy. Among 32 patients who underwent first line FD/Fox treatment, 8 were not evaluable concerning activity: Two patients did not receive at least two cycles of treatment, so they had not yet been evaluated for the disease; one died during the second cycle (not treatment nor disease-related death); one was lost to follow-up and four patients had peritoneal cytology-limited disease. All the activity and efficacy details are listed in Table II. In the ITT analysis, ORR was $75 \%$ and DCR was $87.5 \%$. One patient, in the st FD/FOx subgroup, was not evaluable for efficacy, since he had undergone a neo-adjuvant treatment for locally advanced disease. After a median follow-up of 16 months, median PFS was 14.0 months and median OS was 19.0 months (Fig. 2). Among 22 patients who underwent first line st FD/FOx regimen, 6 were not evaluable for activity. ORR and DCR were 75 and $87.5 \%$, respectively; median PFS and median OS were 14 and 16.0 months, respectively (Fig. 3). Among 10 patients who underwent first line mod FD/FOx regimens, 2 were not evaluable for activity; ORR and DCR were $75 \%$ and DCR $87.5 \%$; median PFS and median OS were 14.0 and 24.0 months, respectively (Fig. 3). ORR, median PFS and median OS of patients treated with st FD/FOx compared to those treated with modified schedules were not significantly different: $\mathrm{P}=1.000$, $\mathrm{P}=0.835$, and $\mathrm{P}=0.380$, respectively (Fig. 4).

Dose intensity. Among all patients, 149 cycles were administered and the median number of administered cycles was 3 (range, 1-8), as well as in st FD/FOx (range 1-8) and mod 
Table I. Patient features.

\begin{tabular}{|c|c|c|c|}
\hline & $\begin{array}{c}\text { Total } \\
\mathrm{N}(\%)\end{array}$ & $\begin{array}{c}\text { Standard schedule } \\
\mathrm{N}(\%)\end{array}$ & $\begin{array}{c}\text { Modified schedule } \\
\mathrm{N}(\%)\end{array}$ \\
\hline Patients (N) & 32 & 22 & 10 \\
\hline \multicolumn{4}{|l|}{ Age (years) } \\
\hline Range & $41-80$ & $43-74$ & $41-80$ \\
\hline Mean & 59.6 & 58.4 & 62.4 \\
\hline Median & 60 & 58.5 & 66.5 \\
\hline \multicolumn{4}{|l|}{ Sex } \\
\hline Male & $23(71.9)$ & $16(72.7)$ & $7(70)$ \\
\hline Female & $9(28.1)$ & $6(27.3)$ & $3(30)$ \\
\hline \multicolumn{4}{|l|}{ Age } \\
\hline Non elderly & $21(65.6)$ & $16(72.7)$ & $5(50)$ \\
\hline Young elderly & $9(28.1)$ & $6(27.3)$ & $3(30)$ \\
\hline Old elderly & $2(6.3)$ & - & $2(20)$ \\
\hline \multicolumn{4}{|l|}{ ECOG-PS } \\
\hline 0 & $10(31.2)$ & $9(40.9)$ & $1(10)$ \\
\hline 1 & $18(56.3)$ & $11(50)$ & $7(70)$ \\
\hline 2 & $4(12.5)$ & $2(9.1)$ & $2(20)$ \\
\hline \multicolumn{4}{|l|}{ CIRS (comorbidity) } \\
\hline Primary & $11(34.4)$ & $10(45.4)$ & $1(10)$ \\
\hline Intermediate & $20(62.5)$ & $12(54.6)$ & $8(80)$ \\
\hline Secondary & $1(3.1)$ & - & $1(10)$ \\
\hline \multicolumn{4}{|l|}{ Hercep test } \\
\hline Positive & $2(6.3)$ & $2(9.1)$ & - \\
\hline Negative & $23(71.9)$ & $15(68.2)$ & $8(80)$ \\
\hline N.V. & $7(21.9)$ & $5(22.7)$ & $2(20)$ \\
\hline \multicolumn{4}{|l|}{ Metastatic disease } \\
\hline Metachronous & $7(21.9)$ & $7(31.8)$ & - \\
\hline Synchronous & $25(78.1)$ & $15(68.2)$ & $10(100)$ \\
\hline Previous ADJ/neoADJ & $2(6.3)$ & $2(9.1)$ & - \\
\hline \multicolumn{4}{|l|}{ Primary tumor } \\
\hline Gastroesophageal junction & $2(6.3)$ & $2(9.1)$ & - \\
\hline Stomach & $30(93.8)$ & $20(90.9)$ & $10(100)$ \\
\hline Locally advanced disease & $1(3.1)$ & $1(4.5)$ & - \\
\hline \multicolumn{4}{|l|}{ Sites of metastasis } \\
\hline Liver & $11(34.4)$ & $6(27.3)$ & $5(50)$ \\
\hline Peritoneum, ascites & $21(65.6)$ & $17(77.3)$ & $4(40)$ \\
\hline Lymph nodes & $17(53.1)$ & $11(50)$ & $6(60)$ \\
\hline Others & $5(15.6)$ & $3(13.6)$ & $2(20)$ \\
\hline Peritoneal cytology only & $4(12.5)$ & $4(18.2)$ & - \\
\hline Unresected primary tumor & $14(43.7)$ & $10(45.4)$ & $4(40)$ \\
\hline
\end{tabular}

ECOG-PS, ECOG-performance status; N.V., not evaluated.

FD/FOx (range, 1-7). Seven patients were treated with 5-FU $1,000 \mathrm{mg} / \mathrm{m}^{2} /$ day for two nights a week as initial dose. Median rDI per cycle in the overall population was: Docetaxel $20(8.5-25) \mathrm{mg} / \mathrm{m}^{2} / \mathrm{w}(80 \%$ of the standard DI), oxaliplatin $32(15-40) \mathrm{mg} / \mathrm{m}^{2} / \mathrm{w}$ (80\% of the standard DI), $5-\mathrm{FU}$ $1,440(375-1,800) \mathrm{mg} / \mathrm{m}^{2} / \mathrm{w}(80 \%$ of the standard DI, referring to the initial dose of $900 \mathrm{mg} / \mathrm{m}^{2} /$ day for two nights a week). All rDIs among patients treated with st and mod FD/FOx are listed in Table III.

Toxicities. All patients were evaluable for safety analysis. The only treatment-related grade 4 adverse event was 
Table II. Activity and efficacy of overall treated patients according to standard and modified regimens.

\begin{tabular}{|c|c|c|c|c|c|c|}
\hline & \multicolumn{2}{|c|}{ Overall } & \multicolumn{2}{|c|}{ St FD/FOx } & \multicolumn{2}{|c|}{ Mod FD/FOx } \\
\hline & $\mathrm{N}$ & $\%$ & $\mathrm{~N}$ & $\%$ & $\mathrm{~N}$ & $\%$ \\
\hline Enrolled patients & 32 & 100 & 22 & 100 & 10 & 100 \\
\hline Evaluable patients & 24 & 75 & 16 & 68.2 & 8 & 90 \\
\hline Objective response rate & \multicolumn{2}{|c|}{$75(95 \%$ CI, 53-90) } & \multicolumn{2}{|c|}{$75(95 \% \text { CI, 48-93 })^{\mathrm{a}}$} & \multicolumn{2}{|c|}{$75(95 \%$ CI, 35-97) } \\
\hline Partial response & 17 & 70.8 & 12 & 75 & 5 & 62.5 \\
\hline Complete response & 1 & 4.2 & - & - & 1 & 12.5 \\
\hline Disease control rate & \multicolumn{2}{|c|}{$87.5(95 \%$ CI, 67.6-97.3) } & \multicolumn{2}{|c|}{$87.5(95 \%$ CI, 61 .6-98.4) } & \multicolumn{2}{|c|}{87.5 (95\% CI, 47.3-99.6) } \\
\hline Stable disease & 3 & 12.5 & 2 & 12.5 & 1 & 12.5 \\
\hline Progression of disease & 3 & 12.5 & 2 & 12.5 & 1 & 12.5 \\
\hline Median PFS (months) & \multicolumn{2}{|c|}{14} & \multicolumn{2}{|c|}{14} & \multicolumn{2}{|c|}{14} \\
\hline Range & \multicolumn{2}{|c|}{$1 \pm 38$} & \multicolumn{2}{|c|}{$1 \pm 38$} & \multicolumn{2}{|c|}{$1 \pm 22$} \\
\hline Progression events & \multicolumn{2}{|c|}{22} & \multicolumn{2}{|c|}{15} & \multicolumn{2}{|c|}{7} \\
\hline Median OS (months) & \multicolumn{2}{|c|}{19} & \multicolumn{2}{|c|}{16} & \multicolumn{2}{|c|}{24} \\
\hline Range & \multicolumn{2}{|c|}{$1 \pm 38$} & \multicolumn{2}{|c|}{$1 \pm 38$} & \multicolumn{2}{|c|}{$1 \pm 38$} \\
\hline Deaths & \multicolumn{2}{|c|}{22} & \multicolumn{2}{|c|}{15} & \multicolumn{2}{|c|}{7} \\
\hline
\end{tabular}

${ }^{\mathrm{a} B i n o m i a l ~ c o n f i d e n c e ~ i n t e r v a l . ~}$
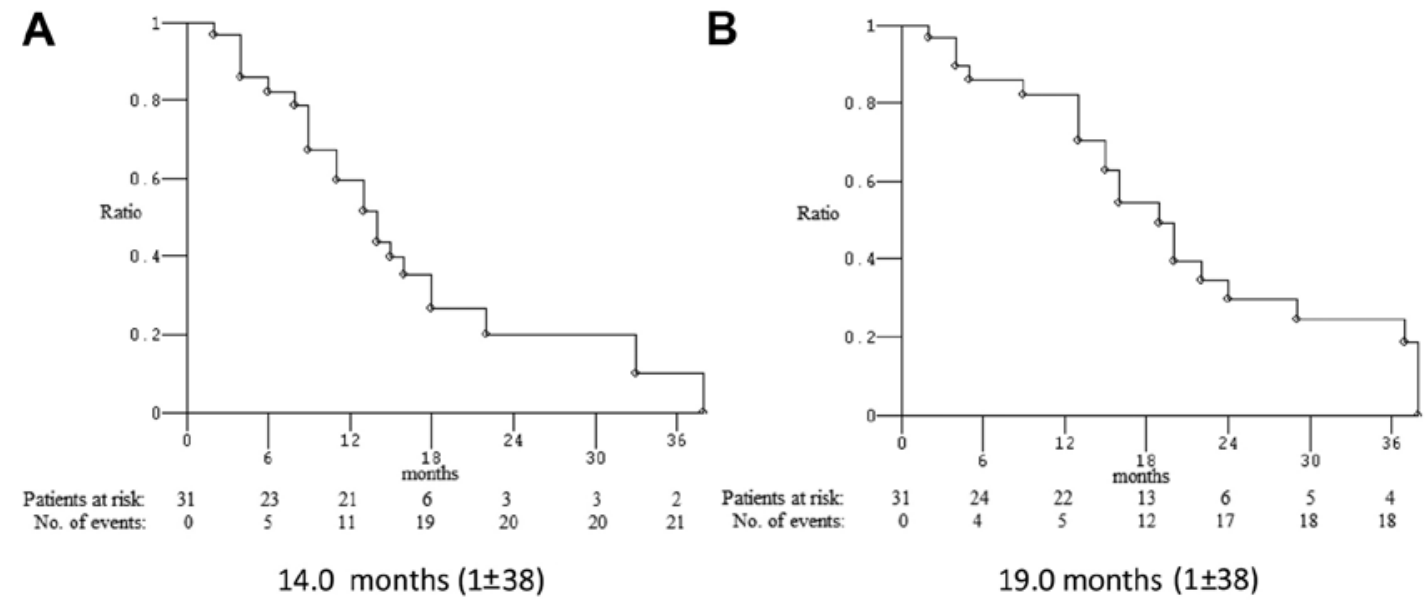

Figure 2. Kaplan-Meier survival estimate. Overall treated patients: (A) Progression-free survival. (B) Overall survival.

neutropenia (9.3\%). Most relevant treatment-related grade 3 adverse events were: Neutropenia (40.6\%), diarrhea $(18.7 \%)$, asthenia (18.7\%). Most relevant grade 2 toxicities were: Nausea (31.1\%), anorexia (40.6\%), asthenia (62.5\%), hypoalbuminemia (43.7\%), peripheral neuropathy (37.5\%), alopecia $(40.6 \%)$, leukopenia $(31.2 \%)$, neutropenia $(59.3 \%)$ and anemia (34.3\%) (Table IV). No febrile neutropenia was observed and none of the patients died as a result of adverse events. No significant differences appeared between the toxicities of st and mod FD/FOx regimens (Table V).

Subsequent treatments. Following the first line FD/FOx, 4 patients $(12.5 \%)$ underwent primary tumor resection. Among the 22 patients who progressed at first line, 13 (59.1\%) underwent a second line chemotherapy as follows: 6 patients (46.1\%) with a taxane-based rechallenge ( 2 with paclitaxel-ramucirumab) and 4 patients $(38.4 \%)$ with irinotecan-based regimens. One patient underwent a third line monotherapy with ramucirumab.

\section{Discussion}

A major problem concerning a triplet chemotherapy is to achieve good clinical outcomes, ensuring an adequate rDI of each drug and concurrently, limiting toxicities. Although DCF is a standard treatment for $\mathrm{a} / \mathrm{m} \mathrm{GC}$ patients, its use is limited in clinical practice, due to the unfavorable safety profile. In our retrospective analysis, ORR was $75 \%$, DCR was $87.5 \%$, median PFS was 14 months and median OS was 19.0 months. The most relevant treatment-related grade 3 adverse events were: Neutropenia (40.6\%), asthenia (18.7\%) and diarrhea $(18.7 \%)$, the only treatment-related grade 4 adverse event was neutropenia $(9.3 \%)$, no febrile neutropenia was observed 
A
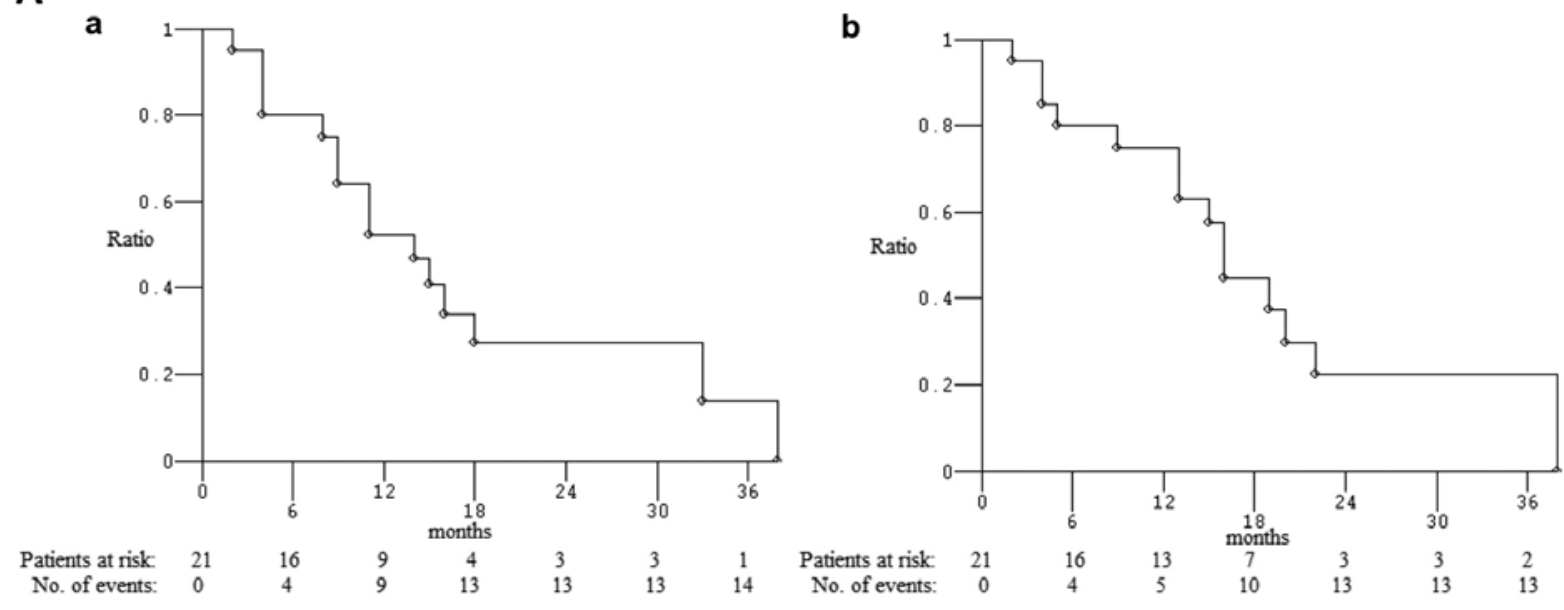

14.0 months $(1 \pm 38)$

16.0 months $(1 \pm 38)$

B

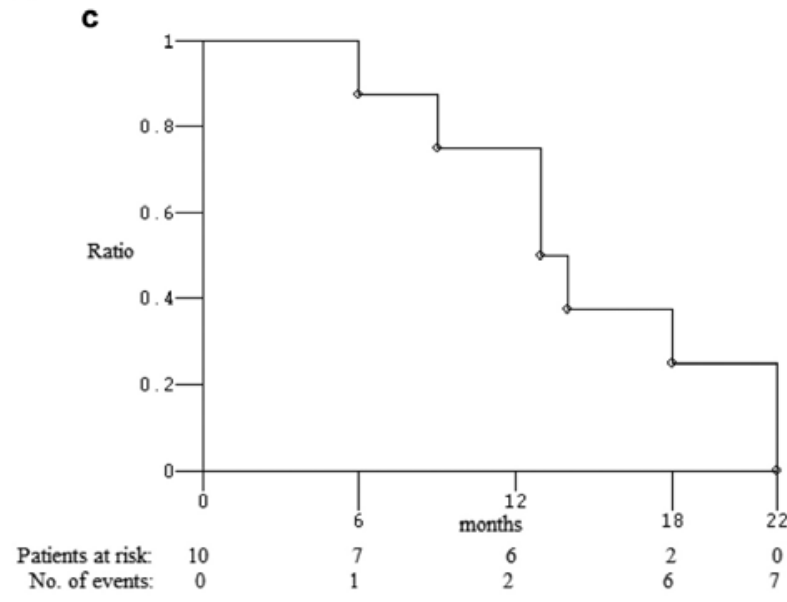

14.0 months $(1 \pm 22)$

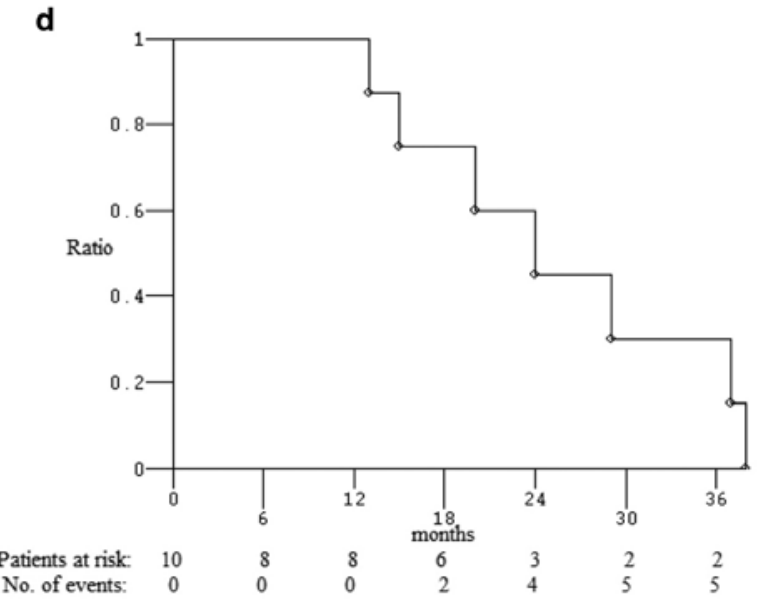

24.0 months $(1 \pm 38)$

Figure 3. Kaplan-Meier survival estimate. (A) Patients treated with standard FD/FOx regimens: (a) Progression-free survival, (b) Overall survival. (B) Patients treated with modified FD/FOx regimens: (c) Progression-free survival, (d) Overall survival.

A

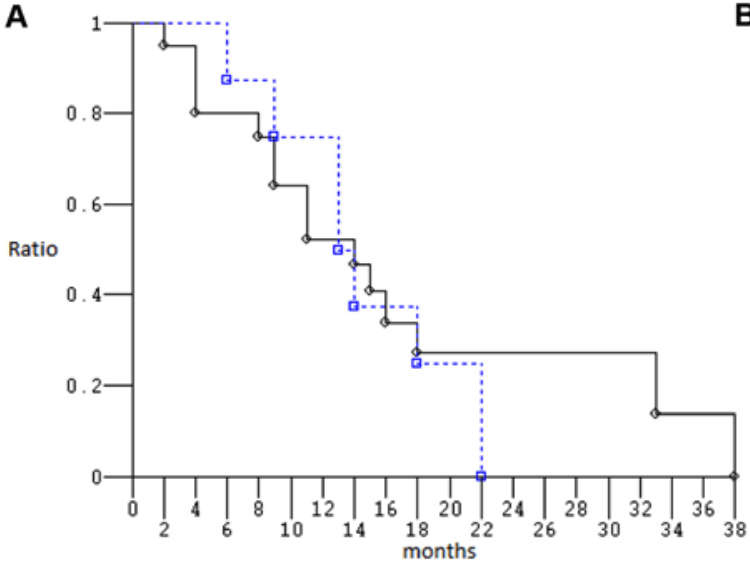

PFS Standard FD/FOx: 14.0 months PFS Modified FD/FOx : 14.0 months $P=0.835$
B

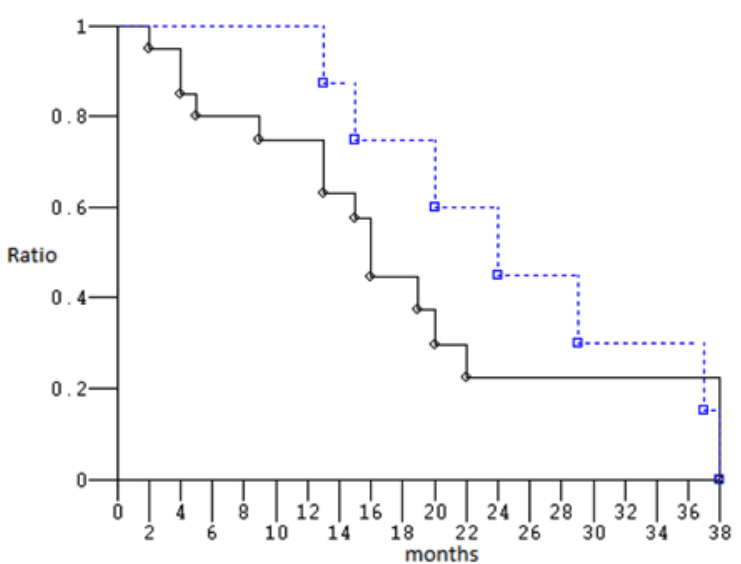

OS Standard FD/FOx: 16.0 months OS Modified FD/FOx: 24.0 months

$\mathrm{P}=0.380$

Figure 4. Kaplan-Meier survival estimate. Standard FD/FOx vs. modified FD/FOx regimens. (A) Progression-free survival. (B) Overall survival. 
Table III. Median received dose intensities in FD/Fox regimens according to standard and modified regimens.

\begin{tabular}{|c|c|c|c|c|c|c|}
\hline & \multicolumn{2}{|c|}{ Overall FD/FOx } & \multicolumn{2}{|c|}{ Standard FD/FOx } & \multicolumn{2}{|c|}{ Modified FD/FOx } \\
\hline & \multicolumn{2}{|c|}{$\mathrm{rDI} /$ cycle $\mathrm{mg} / \mathrm{m}^{2} / \mathrm{w}$} & \multicolumn{2}{|c|}{$\mathrm{rDI} / \mathrm{cycle} \mathrm{mg} / \mathrm{m}^{2} / \mathrm{w}$} & \multicolumn{2}{|c|}{$\mathrm{rDI} /$ cycle $\mathrm{mg} / \mathrm{m}^{2} / \mathrm{w}$} \\
\hline & Median (range) & $\operatorname{rDI}(\%)^{\mathrm{a}}$ & Median (range) & $\mathrm{rDI}(\%)^{\mathrm{a}}$ & Median (range) & $\mathrm{rDI}(\%)^{\mathrm{a}}$ \\
\hline Docetaxel & $20(8.5-25)$ & 80 & $20(8.5-25)$ & 80 & $20(10-25)$ & 80 \\
\hline Oxaliplatin & $32(15-40)$ & 80 & $32(17.5-40)$ & 80 & $32(15-40)$ & 80 \\
\hline $5 \mathrm{FU}$ & $1440(375-1800)$ & 80 & $1500(750-1800)$ & 80 & $1280(375-1800)$ & 71.1 \\
\hline
\end{tabular}

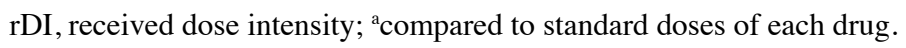

Table IV. Toxicities of standard FD/FOx regimen.

\begin{tabular}{|c|c|c|c|c|}
\hline \multirow[b]{2}{*}{$\mathrm{N}$} & \multicolumn{4}{|c|}{ Overall patients } \\
\hline & \multicolumn{4}{|c|}{32} \\
\hline NCI-CTC grade & 1 & 2 & 3 & 4 \\
\hline Nausea $(\%)$ & $22(68.5)$ & $10(31.2)$ & - & - \\
\hline Vomiting (\%) & $12(37.5)$ & $5(15.6)$ & - & - \\
\hline Diarrhea (\%) & $23(71.8)$ & $5(15.6)$ & $6(18.7)$ & - \\
\hline Anorexia (\%) & $18(56.2)$ & $13(40.6)$ & - & - \\
\hline Constipation (\%) & $11(34.3)$ & $2(6.2)$ & - & - \\
\hline Stomatitis/mucositis (\%) & $16(50)$ & $4(12.5)$ & - & - \\
\hline Asthenia $(\%)$ & $25(78.1)$ & $20(62.5)$ & $6(18.7)$ & - \\
\hline Hypertransaminasemy (\%) & $14(43.7)$ & $1(3.1)$ & - & - \\
\hline Cholestasis $(\%)$ & $13(40.6)$ & $2(6.2)$ & - & - \\
\hline Hypoalbuminemia (\%) & $17(53.1)$ & $14(43.7)$ & - & - \\
\hline Peripheral neuropathy (\%) & $17(53.1)$ & $12(37.5)$ & - & - \\
\hline Skin toxicity $(\%)$ & $3(9.3)$ & - & - & - \\
\hline Onychodystrophy (\%) & $17(53.1)$ & $5(15.6)$ & - & - \\
\hline Alopecia (\%) & $14(43.7)$ & $13(40.6)$ & $3(9.3)$ & - \\
\hline Hand foot syndrome (\%) & $3(9.3)$ & - & - & - \\
\hline Conjunctivitis (\%) & $4(12.2)$ & - & - & - \\
\hline Leukopenia (\%) & $20(62.5)$ & $10(31.2)$ & $3(9.3)$ & - \\
\hline Neutropenia (\%) & $20(62.5)$ & $19(59.3)$ & $10(31.2)$ & $3(9.3)$ \\
\hline Anemia $(\%)$ & $26(81.2)$ & $11(34.3)$ & - & - \\
\hline Thrombocytopenia (\%) & $10(31.2)$ & $2(6.2)$ & - & - \\
\hline
\end{tabular}

and no patients died as a result of adverse events. In addition, no statistically significant differences in ORR, median PFS and median OS, were observed between st and mod FD/Fox regimens.

Despite the intrinsic limits of a retrospective collection, and of the sample size, these data appeared to be slightly better than those deriving from the phase 2 clinical trials previously mentioned $(11,12)$. In the TEF arm of the GATE trial, the most similar regimen to FD/FOx, ORR was $46.6 \%$, median PFS was 7.7 months and median OS was 14.6 months. Furthermore, the most relevant treatment-related grade 3/4 adverse events were: Neutropenia (56\%), leukopenia (30\%) fatigue (14\%) and diarrhea (11\%), whereas febrile neutropenia was reported in $2 \%$ of patients. In a recent systematic review of modified schedules of DCF chemotherapy the median pooled PFS and OS were 7.2 months (95\% CI, 5.9-8.8) and 12.3 months (95\% CI, 10.6-14.3), respectively and the median pooled ORR was $49 \%$. In addition, grade $3 / 4$ toxicities were: Neutropenia $(29.1 \%)$, thrombocytopenia $(5.6 \%)$, anemia $(8.9 \%)$, febrile neutropenia $(7.6 \%)$, diarrhea $(6.6 \%)$, nausea/vomiting (4.9\%) and neurotoxicity (9.9\%) (30). In this study median rDIs of docetaxel, oxaliplatin and 5-FU were respectively 20,32 and $1,440 \mathrm{mg} / \mathrm{m}^{2} /$ week. These results are comparable to those demonstrated in the TEF arm of GATE 
Table V. Toxicities of the FD/FOx regimen according to standard/modified schedules.

\begin{tabular}{|c|c|c|c|c|c|c|c|c|}
\hline \multirow{3}{*}{$\frac{\text { Number }}{\text { NCI-CTC grade }}$} & \multicolumn{4}{|c|}{ St FD/FOx } & \multicolumn{4}{|c|}{ Mod FD/FOx } \\
\hline & \multicolumn{4}{|c|}{22} & \multicolumn{4}{|c|}{10} \\
\hline & 1 & 2 & 3 & 4 & 1 & 2 & 3 & 4 \\
\hline Nausea $(\%)$ & $13(59.1)$ & $4(18.1)$ & - & - & $6(60)$ & $3(30)$ & - & - \\
\hline Vomiting (\%) & $9(40.1)$ & $3(13.6)$ & - & - & $3(30)$ & $2(20)$ & - & - \\
\hline Diarrhea (\%) & $16(72.7)$ & $4(18.1)$ & $5(22.7)$ & - & $7(70)$ & $1(10)$ & $1(10)$ & - \\
\hline Anorexia (\%) & $13(59.1)$ & $8(36.3)$ & - & - & $5(50)$ & $5(50)$ & - & - \\
\hline Constipation (\%) & $8(36.3)$ & $1(4.5)$ & - & - & $3(30)$ & $1(10)$ & - & - \\
\hline Stomatitis/mucositis (\%) & $12(54.5)$ & $3(13.6)$ & - & - & $4(40)$ & $1(10)$ & - & - \\
\hline Asthenia (\%) & $17(77.2)$ & $14(63.6)$ & $4(18.1)$ & - & $8(80)$ & $6(60)$ & $2(20)$ & - \\
\hline Hypertransaminasemy (\%) & $11(50)$ & $1(4.5)$ & - & - & $3(30)$ & - & - & - \\
\hline Cholestasis (\%) & $7(31.8)$ & $1(4.5)$ & - & - & $6(60)$ & $1(10)$ & - & - \\
\hline Hypoalbuminemia (\%) & $10(45.4)$ & $9(40.9)$ & - & - & $7(70)$ & $5(50)$ & - & - \\
\hline Peripheral neuropathy (\%) & $19(86.3)$ & $4(18.1)$ & - & - & $8(80)$ & - & - & - \\
\hline Skin toxicity $(\%)$ & $3(13.6)$ & - & - & - & - & - & - & - \\
\hline Onychodystrophy (\%) & $11(50)$ & $5(22.7)$ & - & - & $6(60)$ & - & - & - \\
\hline Alopecia (\%) & $7(31.8)$ & $11(50)$ & $1(4.5)$ & - & $7(70)$ & $2(20)$ & $2(20)$ & - \\
\hline Hand foot syndrome (\%) & $3(13.6)$ & - & - & - & - & - & - & - \\
\hline Conjunctivitis (\%) & $4(18.1)$ & - & - & - & - & - & - & - \\
\hline Leukopenia (\%) & 14 (63.6) & $7(31.8)$ & $2(9.1)$ & - & $6(60)$ & $3(30)$ & $1(10)$ & - \\
\hline Neutropenia (\%) & $14(63.6)$ & $14(63.6)$ & $8(36.3)$ & $2(9.1)$ & $6(60)$ & $5(50)$ & $2(20)$ & $1(10)$ \\
\hline Anemia $(\%)$ & $18(81.8)$ & $7(31.8)$ & - & - & $8(80)$ & $4(40)$ & - & - \\
\hline Thrombocytopenia (\%) & $6(27.2)$ & $1(4.5)$ & - & - & $4(40)$ & $1(10)$ & - & - \\
\hline
\end{tabular}

trial $\left(20,33\right.$ and $966 \mathrm{mg} / \mathrm{m}^{2} /$ week) regarding docetaxel and oxaliplatin and even higher regarding 5-FU (12). The use of TFI/5-FU, and weekly-alternating docetaxel and oxaliplatin, allowed us to reach these results, with an acceptable safety profile, especially in terms of hematologic toxicity and neurotoxicity. Since it was retrospective study of clinical practice, even elderly patients with poor clinical conditions were considered: 4 (12.5\%) patients had an ECOG-PS 2 and $11(34.4 \%)$ patients were elderly. Dose modulations allowed us to treat these patients as well. According to our opinion, patients with severe comorbidities are not eligible for intensive regimens: Only one patient (treated with mod FD/FOx) had a secondary CIRS stage. Even though the weekly rate of the regimen represented a greater engagement both for patients and their families, and a greater workload for the outpatient clinic, it allowed us to carefully monitor treatment and adverse events.

$\mathrm{A} / \mathrm{m}$ GC patients and particularly those with unresected primary tumor and/or peritoneal carcinomatosis (44 and $66 \%$, respectively of our population) typically dropped out of treatment precociously, due to the deterioration of the clinical conditions, as well as developing nutritional problems such as anorexia, dysphagia, vomiting and slimming. Considering that these patients often do not reach a second line of treatment, they probably need rapid tumor shrinkage in order to palliate symptoms. Concurrently, an adequate nutritional support and a careful management of toxicities, which can be particularly severe in malnourished patients, are mandatory.
In our case-series, among 14 patients with unresected primary tumors, 4 (28.5\%) underwent resection of the primary tumor and among the 22 patients who progressed on the FD/FOx regimen, $13(59 \%)$ underwent a second line of treatment, $46 \%$ of which taxane-based, with or without ramucirumab.

In the second-line setting of $\mathrm{a} / \mathrm{m} \mathrm{GC}$ patients, the advent of ramucirumab, a fully human monoclonal antibody against the vascular endothelial growth factor receptor (VEGFR)-2, set a new standard of care in patients progressing after a platinum-based first-line therapy. Ramucirumab in two large international phase III multicenter studies demonstrated benefits in median OS, median PFS and DCR compared to BSC (REGARD trial). It also demonstrated benefits in median OS, median PFS, ORR and DCR in association with paclitaxel compared to paclitaxel alone (RAINBOW trial) $(31,32)$.

Ultimately, a triplet chemotherapy cannot always be used and it is crucial to select patients eligible for an intensive regimen. The features of patients (age, expected QoL, prolonged survival) and those of the disease (tumor burden, symptoms) play a central role in the decision-making process, and the use of validate prognostic factors such as the Royal Marsden Hospital prognostic index or similar could aid clinicians $(33,34)$. Therefore, a taxane could be used in the first-line setting, in combination with platinum compounds and fluoropyrimidines in 'high risk' patients. These patients will probably not reach a second line (i.e. with ECOG-PS 2, liver metastasis, peritoneal metastasis, increase of alkaline phosphatase), and frequently need a rapid relief of symptoms 
due to high tumor burden. However, a triplet regimen should be excluded in cases of severe (or uncontrolled) comorbidities. Otherwise a taxane should be used in second line, associated with ramucirumab, in 'low risk' patients (i.e. with none of the risk factors mentioned above), with a better prognosis, following progression to a first line treatment based on platinum compounds and fluoropyrimidines, by modulating the treatment in view of this potential second line. Both choices could be correct in 'intermediate risk' patients (i.e. patients with 1-2 of the risk factors mentioned above).

In conclusion, the retrospecive nature, the small sample size and the mixed population (4 patients with peritoneal cytology-limited disease) were strong limitations, which did not allow us to reach any conclusive considerations, nevertheless the FD/FOx regimen has become a common clinical practice in our institute. In our opinion it appears to be a feasible option for first-line treatment of a/m GC patients, especially in case of high tumour burden, when the patient needs rapid tumour shrinkage and disease-related symptoms control. TFI/5-FU and dose modulations have probably allowed us to use an intensive regimen in clinical practice even in elderly and 'frail' patients, with comorbidities and ECOG-PS 1-2. TFI could be an alternative and an easy modality of administration of 5-FU, which still represents the backbone of the first-line regimen for treating a/m GC patients.

\section{Acknowledgements}

Not applicable.

\section{Funding}

No funding was received.

\section{Availability of data and materials}

The datasets used during the present study are available from the corresponding author upon reasonable request.

\section{Authors' contributions}

$\mathrm{AC}, \mathrm{KC}, \mathrm{GP}$ and $\mathrm{CF}$ conceived and designed the study. AP, RV, VV, BDB, OV, PLB and LV collected the data. AC and AP wrote the paper. $\mathrm{CF}$ and GP reviewed and edited the manuscript. All authors read and approved the manuscript and agree to be accountable for all aspects of the research in ensuring that the accuracy or integrity of any part of the work are appropriately investigated and resolved.

\section{Ethics approval and consent to participate}

All patients provided written, informed consent to treatment. The procedures followed were in accordance with the ethical standards of the local responsible committees on human experimentation (Comitato etico per le province di L'Aquila e Teramo).

\section{Patient consent for publication}

Not applicable.

\section{Competing interests}

The authors state that they have no competing interests.

\section{References}

1. Murad AM, Santiago FF, Petroianu A, Rocha PR, Rodrigues MA and Rausch M: Modified therapy with 5-fluorouracil, doxorubicin, and methotrexate in advanced gastric cancer. Cancer 72 : 37-41, 1993.

2. Pyrhönen S, Kuitunen T, Nyandoto P and Kouri M: Randomised comparison of fluorouracil, epidoxorubicin and methotrexate (FEMTX) plus supportive care with supportive care alone in patients with non-resectable gastric cancer. Br J Cancer 71: 587-591, 1995.

3. Koizumi W, Narahara H, Hara T, Takagane A, Akiya T, Takagi M, Miyashita K, Nishizaki T, Kobayashi O, Takiyama W, et al: S-1 plus cisplatin versus S-1 alone for first-line treatment of advanced gastric cancer (SPIRITS trial): A phase III trial. Lancet Oncol 9: 215-221, 2008.

4. Levi JA, Fox RM, Tattersall MH, Woods RL, Thomson D and Gill G: Analysis of a prospectively randomized comparison of doxorubicin versus 5-fluorouracil, doxorubicin, and BCNU in advanced gastric cancer: Implications for future studies. J Clin Oncol 4: 1348-1355, 1986.

5. Bang YJ, Van Cutsem E, Feyereislova A, Chung HC, Shen L, Sawaki A,LordickF, Ohtsu A, Omuro Y,Satoh T, et al: Trastuzumab in combination with chemoterapy versus chemoterapy alone for treatment of HER2-positive advanced gastric or gastro-oesophageal junction cancer (ToGA): A phase 3, open label, randomised controlled trial. Lancet 376: 687-697, 2010.

6. Ajani JA, D'Amico TA, Baggstrom M, Bentrem DJ, Chao J, Das P, Denlinger CS, Enzinger PC, Fanta P, Farjah F, et al: Clinical practice guidelines in oncology, gastric cancer. National Comprehensive Cancer Network, version 4, 2017.

7. Smyth EC, Verheij M, Allum W, Cunningham D, Cervantes A and Arnold D; ESMO Guidelines Committee: Gastric cancer: ESMO clinical practice guidelines for diagnosis, treatment and follow-up. Ann Oncol 27 (Suppl 5): v38-v49, 2016.

8. Mohammad NH, Ter Veer E, Ngai L, Mali R, van Oijen MG and van Laarhoven HW: Optimal first-line chemotherapeutic treatment in patients with locally advanced or metastatic esophagogastric carcinoma: Triplet versus doublet chemotherapy: A systematic literature review and meta-analysis. Cancer Metastasis Rev 34: 429-441, 2015.

9. Carmona-Bayonas A, Jiménez-Fonseca P, Custodio A, Sánchez Cánovas M, Hernández R, Pericay C, Echavarria I, Lacalle A, Visa L, Rodríguez Palomo A, et al: Anthracycline-based triplets do not improve the efficacy of platinum-fluoropyrimidine doublets in first-line treatment of advanced gastric cancer: Real-world data from the AGAMEMON National cancer Registry. Gastric Cancer 21: 96-105, 2018.

10. Ter Veer E, Haj Mohammad N, van Valkenhoef G, Ngai LL, Mali RMA, Anderegg MC, van Oijen MGH and van Laarhoven HWM: The efficacy and safety of first-line chemotherapy in advanced esophagogastric cancer: A Network Meta-analysis. J Natl Cancer Inst: 108, 2016.

11. Shah MA, Janjigian YY, Stoller R, Shibata S, Kemeny M, Krishnamurthi S, Su YB, Ocean A, Capanu M, Mehrotra B, et al: Randomized multicenter phase II study of modified docetaxel, cisplatin, and fluorouracil (DCF) versus DCF plus growth factor support in patients with metastatic gastric adenocarcinoma: A study of the US gastric cancer consortium. J Clin Oncol 33: 3874-3879, 2015.

12. Van Cutsem E, Boni C, Tabernero J, Massuti B, Middleton G, Dane F, Reichardt P, Pimentel FL, Cohn A, Follana P, et al: Docetaxel plus oxaliplatin with or without fluorouracil or capecitabine in metastatic or locally recurrent gastric cancer: A randomized phase II study. Ann Oncol 26: 149-156, 2015.

13. Al-Batran SE, Hofheinz RD, Pauligk C, Kopp HG, Haag GM, Luley KB, Meiler J, Homann N, Lorenzen S, Schmalenberg $\mathrm{H}$, et al: Histopathological regression after neoadjuvant docetaxel, oxaliplatin, fluorouracil, and leucovorin versus epirubicin, cisplatin, and fluorouracil or capecitabine in patients with resectable gastric or gastro-oesophageal junction adenocarcinoma (FLOT4-AIO): Results from the phase 2 part of a multicentre, open-label, randomised phase $2 / 3$ trial. Lancet Oncol 17: 1697-1708, 2016. 
14. Ficorella C, Ricevuto E, Morelli MF, Morese R, Cannita K, Cianci G, Porzio G, Di Rocco ZC, De Galitiis F, De Tursi M, et al: Increased tolerability of bimonthly 12-hour timed flat infusion 5-fluorouracil/irinotecan regimen in advanced colorectal cancer: A dose-finding study. Oncol Rep 15: 1345-1350, 2006.

15. Ficorella C, Bruera G, Cannita K, Porzio G, Baldi PL, Tinari N, Natoli $\mathrm{C}$ and Ricevuto E: Triplet chemotherapy in patients with metastatic colorectal cancer: Toward the best way to safely administer a highly active regimen in clinical practice. Clin Colorectal Cancer 11: 229-237, 2012.

16. Köhne CH1, Wils J, Lorenz M, Schöffski P, Voigtmann R, Bokemeyer C, Lutz M, Kleeberg C, Ridwelski K, Souchon R, et al: Randomized phase III study of high-dose fluorouracil given as a weekly 24-hour infusion with or without leucovorin versus bolus fluorouracil plus leucovorin in advanced colorectal cancer: European organization of Research and Treatment of Cancer Gastrointestinal Group Study 40952. J Clin Oncol 21: 3721-3728, 2003.

17. Leichman CG, Fleming TR, Muggia FM, Tangen CM, Ardalan B, Doroshow JH, Meyers FJ, Holcombe RF, Weiss GR, Mangalik A, et al: A phase II study of fluorouracil and its modulation in advanced colorectal cancer: A Southwest oncology group study. J Clin Oncol 13: 1303-1311, 1995.

18. O'Dwyer PJ, Manola J, Valone FH, Ryan LM, Hines JD, Wadler S, Haller DG, Arbuck SG, Weiner LM, Mayer RJ and Benson AB III: Fluorouracil modulation in colorectal cancer: Lack of improvement with $\mathrm{N}$-phosphonoacetyl-l-aspartic acid or oral leucovorin or interferon, but enhanced therapeutic index with weekly 24-h infusion schedule-An eastern cooperative oncology group/cancer and leukemia Group B study. J Clin Oncol 19: 2413-2421, 2001.

19. Lévi F: Chronopharmacology of anticancer agents. In Redfern PH, Lemmer B, eds. Handbook of Exeperimental pharmacology: Physiology and pharmacology of biological Rhythms-cancer chemotherapy. Springer-Verlag, Berlin, pp299-301, 1997

20. Harris BE, Song R, Soong SJ and Diasio RB: Relationship between dihydropyrimidine dehidrogenase activity and plasma 5-fluorouracil levels with evidence for circadian varation of enzyme activity and plasma drug levels in cancer patients receiving 5 -fluorouracil by protracted continuous infusion. Cancer Res 50: 197-201, 1990.

21. Smaaland R, Abrahamsen JF, Svardal AM, Lote K and Ueland PM: DNA cell cycle distrubution and glutathione (GSH) content according to circadian stage in bone marrow of cancer patients. Br J Cancer 66: 39-45, 1992

22. Morelli MF, Santomaggio A, Ricevuto E, Cannita K, De Galitiis F, Tudini M, Bruera G, Mancini M, Pelliccione M Calista F, et al: Triplet schedule of weekly 5-Fluorouracil and alternating irinotecan or oxaliplatin in advanced colorectal cancer: A dose-finding and phase II study. Oncol Rep 23 . $1635-1640,2010$.
23. Bruera G, Santomaggio A, Cannita K, Baldi PL, Tudini M, De Galitiis F, Mancini M, Marchetti P, Antonucci A, Ficorella C and Ricevuto E: 'Poker' association of weekly alternating 5-fluorouracil, irinotecan, bevacizumab and oxaliplatin (FIr-B/FOx) in first line treatment of metastatic colorectal cancer: A phase II study. BMC Cancer 10: 567, 2010.

24. Extermann M, Overcash J, Lyman GH, Parr J and Balducci L: Comorbidity and functional status are independent in older cancer patients. J Clin Oncol 16: 1582-1587, 1998.

25. Washington K: 7th edition of the AJCC cancer staging manual: Stomach. Ann Surg Oncol 17: 3077-3079, 2010.

26. Therasse P, Arbuck SG, Eisenhauer EA, Wanders J, Kaplan RS, Rubinstein L, Verweij J, Van Glabbeke M, van Oosterom AT, Christian MC and Gwyther SG: New guidelines to evaluate the response to treatment in solid tumors: European organization for research and treatment of cancer, National Cancer Institute of the United States, National Cancer Institute of Canada. J Natl Cancer Inst 92: 205-216, 2000.

27. Kaplan EL and Meier P: Nonparametric estimation of incomplete observations. J Am Stat Assoc 53: 457-481, 1958.

28. Fisher RA: On the interpretation of $\chi 2$ from contingency tables, and the calculation of P". J R Stat Soc 85: 87-94, 1922.

29. Peto R and Peto J: Asymptomatically efficient rank invariant test procedures. J R Stat Soc A 135: 185-207, 1972.

30. Petrelli F, Tomasello G, Ghidini M, Passalacqua R and Barni S: Modified schedules of DCF chemotherapy for advanced gastric cancer: A systematic review of efficacy and toxicity. Anticancer Drugs 28: 133-141, 2017.

31. Fuchs CS, Tomasek J, Yong CJ, Dumitru F, Passalacqua R, Goswami C, Safran H, Dos Santos LV, Aprile G, Ferry DR, et al: Ramucirumab monotherapy for previously treated advanced gastric or gastro-oesophageal junction adenocarcinoma (REGARD): An international, randomised, multicentre, placebo-controlled, phase 3 trial. Lancet 383: 31-39, 2014.

32. Wilke H, Muro K, Van Cutsem E, Oh SC, Bodoky G, Shimada Y, Hironaka S, Sugimoto N, Lipatov O, Kim TY, et al: Ramucirumab plus paclitaxel versus placebo plus paclitaxel in patients with previously treated advanced gastric or gastro-oesophageal junction adenocarcinoma (RAINBOW): A double-blind, randomised phase 3 trial. Lancet Oncol 15: 1224-1235, 2014

33. Chau I, Ashley S and Cunningham D: Validation of the Royal Marsden hospital prognostic index in advanced esophagogastric cancer using individual patient data from the REAL 2 study. J Clin Oncol 27: e3-e4, 2009

34. Fuchs CS, Muro K, Tomasek J, Van Cutsem E, Cho JY, Oh SC, Safran H, Bodoky G, Chau I, Shimada Y, et al: Prognostic factor analysis of overall survival in gastric cancer from two phase III studies of Second-line Ramucirumab (REGARD and RAINBOW) using pooled patient data. J Gastric Cancer 17: 132-144, 2017. 